\title{
Knowledge and Expectations on Antibiotic Use Among the General Public in Malaysia: A Nationwide Cross-Sectional Survey
}

\author{
Lai San Kong' \\ Farida Islahudin' \\ Leelavathi Muthupalaniappen ${ }^{2}$ \\ Wei Wen Chong' \\ 'Centre of Quality Management of \\ Medicines, Faculty of Pharmacy, Universiti \\ Kebangsaan Malaysia, Kuala Lumpur, \\ 50300, Malaysia; ${ }^{2}$ Department of Family \\ Medicine, Medical Faculty, Universiti \\ Kebangsaan Malaysia, Kuala Lumpur, \\ 56000, Malaysia
}

Background: Identifying knowledge gaps regarding antibiotic use and resistance is important for future interventional strategies. There is limited information on Malaysia's general public's knowledge and expectations on antibiotic use.

Purpose: To assess the knowledge of antibiotic use and resistance, expectations from antibiotic prescription, and identify inappropriate practices related to antibiotic use among Malaysia's general public.

Materials and Methods: A nationwide cross-sectional survey was conducted among Malaysians aged 18 years and above from each state, from May to November 2019. Participants were recruited via quota sampling, followed by convenient sampling. A validated self-administered questionnaire was used to collect data.

Results: Of the 1971 respondents recruited, 56.6\% had engaged in at least one inappropriate practice; particularly, not completing the antibiotic course $(48.8 \%)$. The mean total knowledge score was $8.57 \pm 4.24$ (total 20). The majority incorrectly believed that antibiotics work on viral infections $(79.1 \%)$ and colds and coughs $(77.0 \%)$. Less than half of them believed that antibiotics could be stopped when symptoms improved (42.8\%). Most respondents incorrectly perceived that antibiotic resistance occurs when the body becomes resistant to antibiotics (90.2\%) and antibiotic resistance is not an issue in the country (62.9\%). More than half the participants expected antibiotics to be prescribed for self-limiting symptoms (fever: $62.9 \%$, sore throat: $57.2 \%$, cold or flu: $50.9 \%$ ). Respondents with better knowledge were less likely to engage in inappropriate antibiotic use (never engaged: $9.26 \pm 4.40$ versus had engaged: $8.11 \pm 4.00, \mathrm{p}<0.001)$, and expect doctors to discuss with them the need for antibiotics (agree/strongly agree: $9.03 \pm 4.25$ versus neutral: $6.62 \pm 3.91$ versus disagree/ strongly disagree: $8.29 \pm 4.00, \mathrm{p}<0.001)$.

Conclusion: Knowledge gaps in the role of antibiotics and understanding of antibiotic resistance should be considered whtpen designing future educational strategies for the general public.

Keywords: antibiotic use, antibiotic resistance, knowledge, expectation, inappropriate practice, general public

\section{Introduction}

Antibiotic resistance is a severe global problem, and the World Health Organization (WHO) has called for urgent actions to be taken by all countries to combat it. ${ }^{1}$ Antibiotic resistance occurs when antibiotics are no longer effective in eradicating microorganisms. Although this is an inevitable natural process that cannot be entirely eliminated, steps can be taken to slow down its emergence and spread. ${ }^{2}$
Correspondence: Wei Wen Chong

Faculty of Pharmacy, Universiti Kebangsaan Malaysia, Kuala Lumpur. 50300, Malaysia

Tel $+603-9289-7118$

Email weiwen@ukm.edu.my 
The adverse impacts of antibiotic resistance on the community's health and global economics are devastating and severe, as increased morbidity and mortality will increase the burden on healthcare costs and loss of productivity. ${ }^{3,4}$

A major contributing factor to antibiotic resistance is the inappropriate use of antibiotics. ${ }^{5}$ The lack of knowledge and incorrect attitudes toward antibiotic use among the general public is responsible for antibiotic resistance. ${ }^{6}$ Poor knowledge of antibiotic use was associated with a higher probability of inappropriate practice, including self-medication, using leftover antibiotics, sharing antibiotics, keeping antibiotics for future use, and stopping antibiotics when symptoms disappear. ${ }^{7-9}$ Local studies have reported that some of the public had ever obtained antibiotics without prescription to self-medicate, mainly from community pharmacies or private clinics. ${ }^{10-12}$ Although strict regulations are enforced in Malaysia where antibiotics must be sold or dispensed only with a prescription, the easy accessibility to antibiotics implies that more actions need to be taken to promote prudent antibiotic use in the community. ${ }^{13}$

In Malaysia, knowledge of antibiotic use among the general public was reported to be poor to moderate. ${ }^{14-16}$ Knowledge gap was observed, where antibiotics were thought to be useful in treating viral infections such as common cold and cough. ${ }^{11,15-20}$ There was also low awareness and inaccurate understanding of antibiotic resistance both in Malaysia and other countries. ${ }^{19,21-24}$ Most of the general public had heard about antibiotic resistance but misunderstood it as the body being resistant to antibiotics. ${ }^{19,21,22,25,26}$ Although some of them recognized that overuse and incomplete use of antibiotics are responsible for antibiotic resistance, their perceived seriousness and awareness on the consequences of antibiotic resistance to their own family, communities, and country, as well as their self-accountability to reduce its spread, were low. ${ }^{19,21,22,25-27}$

Patients' expectations and demand for antibiotics were determinants of unnecessary antibiotic prescriptions by physicians. ${ }^{28}$ Most patients who visited a physician and expected an antibiotic for their self-limiting symptoms would receive one. However, many patients do not complete the course of the antibiotic. ${ }^{29}$ Links between the patients' knowledge and expectations for antibiotics have been reported, where those who correctly identified that antibiotics were not effective for symptoms of viral infections were less likely to expect antibiotics from their doctors. $^{20,30,31}$
In response to the WHO's call to combat antibiotic resistance, Malaysia released a 5-year action plan on antimicrobial resistance in 2017. Various measures have been implemented to promote correct antibiotic use and increase awareness of antibiotic resistance among the general public and healthcare providers. Among the measures carried out was implementing antimicrobial stewardship by providing professional training and education to healthcare providers in private and public health facilities. In addition, health promotion to the public has been conducted through mass media, electronic media, social media, the "Know Your Medicine" public health campaigns and the annual World Antibiotic Awareness Week. ${ }^{32}$ Although previous studies have assessed the knowledge and practices of antibiotic use among the Malaysian general public, most of these studies were conducted at a single center and among the urban population, limiting the generalizability of the findings to the entire Malaysian population. Hence, this study aimed to assess the knowledge, expectations, and practices related to antibiotic use in Malaysia by recruiting respondents in a way that would be more representative of the Malaysian public in general.

\section{Materials and Methods Study Design and Sampling}

A cross-sectional survey was conducted from May to November 2019 in public areas from all states in Malaysia. Malaysian citizens aged 18 years and above were invited to participate in the study. To identify a representative sample of the Malaysian general public, quota sampling based on the actual population's age group, gender, ethnicity, state of residence, and geographic area (urban and rural) was applied. These data were obtained from the ten-yearly census in 2010 from the Department of Statistics Malaysia. ${ }^{33}$ In 2019, 71.3\% (22.78 million) of the total population of 31.95 million Malaysians were more than 18 years old. ${ }^{34}$ Using the Raosoft sample size calculator with a margin of error of $5 \%$, a confidence interval of $95 \%$, and a response distribution of $50 \%$, the minimum estimated sample size was $385 .^{35}$ The sample size was then doubled as a response rate of $50 \%$ was expected owing to convenience sampling in public areas. As Malaysia is a multiethnic country, to ensure the generalizability and heterogeneity of samples from both urban and rural areas, a minimum of 1500 Malaysian citizens were targeted. This would provide 
a margin of error of $2.5 \%$ and a confidence interval of $95 \%$.

\section{Questionnaire Instrument}

A questionnaire was developed based on a review of validated questionnaires from previous studies. ${ }^{16,17,25,36}$ The questionnaire was reviewed by an expert panel consisting of an infectious disease consultant and two senior infectious disease pharmacists for content validity. The final questionnaire consisted of four sections. Section A consisted of questions on respondents' demographic characteristics. Questions about past experiences of antibiotic use and engagement in inappropriate practices related to antibiotic use were assessed in Section B. Section C consisted of 20 items related to knowledge of antibiotic use (12 items) and antibiotic resistance (eight items). The items contained a mixture of true and false statements regarding antibiotics. One point was given for each correct answer, and zero for the wrong answer or if the respondent selected the "Not Sure" option. The minimum score for the knowledge section was 0 , and the maximum score was 20. Section D consisted of items related to respondents' expectations to receive antibiotic prescription based on symptoms (Part I, seven items), for which respondents were instructed to select "Yes," "No" or "Not Sure." Part II (four items) of this section assessed respondents' expectations regarding antibiotic prescription by their physicians by indicating their level of agreement on a five-point Likert scale ("Strongly Disagree," "Disagree," "Neutral," "Agree" and "Strongly Agree").

The questionnaire was initially developed in English and translated into Bahasa Malaysia, which is the national language, as well as Mandarin, and Tamil languages to cater to the multiethnic population using the forwardbackward translation method. A pilot test was conducted with 30 respondents to assess the clarity and reliability of the questionnaires. The internal consistency for the questionnaire using Cronbach's $\alpha$ test was 0.797 for the knowledge section (Section C) and 0.798 for the section on expectations of antibiotics prescribed based on symptoms (Section D, Part I).

\section{Data Collection}

Ethical approval for this study was obtained from the Universiti Kebangsaan Malaysia (UKM) Research Ethics Committee (reference number: UKM PPI/111/8/JEP-2018717). The study was conducted in accordance with the Declaration of Helsinki. To achieve generalizability of the findings, trained research assistants distributed the questionnaires to the general public in different public places such as shops, markets, transport stations, town libraries, parks, restaurants, etc., in both rural and urban areas of each state. The urbanization level in Malaysia was reported to be $76.6 \%$ in $2020 .{ }^{37}$ The definition and latest list of urban and rural areas were obtained and confirmed via calls and emails to the Federal Department of Town and Country Planning, Ministry of Housing and Local Government, Malaysia. Then, the selection of urban and rural areas from each state was decided after discussions with the research assistants based on their accessibility. Potential respondents were identified, and the purpose of the study was explained to them face-to-face before obtaining their written consent. The questionnaire was completed and returned to the research assistants. No personal identification details of the respondents were included in this study. Respondents' participation was voluntary, and their responses were managed with a high level of confidentiality and anonymity.

\section{Data Analysis}

Data were analyzed using IBM Statistical Package for Social Sciences (SPSS) Statistics version $26 .{ }^{38}$ Respondents' demographic characteristics, experience with antibiotic use, knowledge of antibiotic use and resistance, and expectations related to antibiotic use were analyzed descriptively. As the data was normally distributed, independent $\mathrm{t}$-tests were used to assess the differences in total knowledge scores between groups with appropriate and inappropriate antibiotic-related practices. One-way Analysis of Variance (ANOVA) tests were used to assess the differences in total knowledge scores between responses on expectations of antibiotic prescription by their physicians. The chi-square test was used to assess the association between respondents' knowledge of the role of antibiotics and their expectation of being prescribed antibiotics for cold, flu, or cough. A p-value of $<0.05$, with a confidence interval of $95 \%$, was considered statistically significant.

\section{Results}

A total of 1971 respondents were recruited from all 14 states in Malaysia. The demographic characteristics of the respondents are presented in Table 1. The respondents' mean age was $36.88 \pm 14.75$. years, and female respondents $(n=1040,52.8 \%)$ were slightly more than male respondents $(n=931,47.2 \%)$. The majority of them were 
Table I Demographic Characteristics of Respondents $(\mathrm{n}=$ 197I)

\begin{tabular}{|c|c|}
\hline Respondents' Characteristics & Study, n (\%) \\
\hline Age, mean \pm SD & $36.88 \pm 14.75$ \\
\hline 18-39 years old & $1196(60.68 \%)$ \\
\hline $40-59$ years old & $573(29.07 \%)$ \\
\hline$\geq 60$ years old & $202(10.25 \%)$ \\
\hline \multicolumn{2}{|l|}{ Gender } \\
\hline Male & $931(47.2 \%)$ \\
\hline Female & $1040(52.8 \%)$ \\
\hline \multicolumn{2}{|l|}{ Ethnicity* } \\
\hline Bumiputra & 1364 (69.2\%) \\
\hline Chinese & $399(20.2 \%)$ \\
\hline Indian & 170 (8.6\%) \\
\hline Others & 38 (1.9\%) \\
\hline \multicolumn{2}{|l|}{ Educational level } \\
\hline No formal education & $19(1.0 \%)$ \\
\hline Primary education & 91 (4.6\%) \\
\hline Secondary education & $728(36.9 \%)$ \\
\hline Pre-university education & $322(16.3 \%)$ \\
\hline Tertiary education & $811(41.1 \%)$ \\
\hline \multicolumn{2}{|l|}{ Main occupation } \\
\hline Unemployed & 118 (6.0\%) \\
\hline Employed for wages & $934(47.4 \%)$ \\
\hline Self-employed & $280(14.2 \%)$ \\
\hline Housewife/Househusband & $15 \mathrm{I}(7.7 \%)$ \\
\hline Student & 349 (17.7\%) \\
\hline Retiree & 139 (7.1\%) \\
\hline \multicolumn{2}{|l|}{ Occupation related to healthcare } \\
\hline Yes & 147 (7.5\%) \\
\hline No & 1824 (92.5\%) \\
\hline \multicolumn{2}{|l|}{ Monthly income } \\
\hline None & $654(33.2 \%)$ \\
\hline$<$ RM 1000 & $217(11.0 \%)$ \\
\hline RM 1000 - RM 3999 & $756(38.4 \%)$ \\
\hline RM 4000 - RM 6999 & $24 I(12.2 \%)$ \\
\hline RM 7000 - RM 9999 & $64(3.2 \%)$ \\
\hline$\geq$ RM 10,000 & $39(2.0 \%)$ \\
\hline \multicolumn{2}{|l|}{ Residence status (Geographic area) } \\
\hline Urban & 1502 (76.2\%) \\
\hline Rural & $469(23.8 \%)$ \\
\hline \multicolumn{2}{|l|}{ State of residency } \\
\hline Perlis & 17 (0.9\%) \\
\hline Kedah & 112 (5.7\%) \\
\hline Pulau Pinang & $120(6.1 \%)$ \\
\hline Perak & $138(7.0 \%)$ \\
\hline Selangor & $495(25.1 \%)$ \\
\hline Negeri Sembilan & 45 (2.3\%) \\
\hline Melaka & $62(3.1 \%)$ \\
\hline
\end{tabular}

(Continued)
Table I (Continued).

\begin{tabular}{|l|c|}
\hline Respondents' Characteristics & Study, n (\%) \\
\hline Johor & $217(11.0 \%)$ \\
Pahang & $113(5.7 \%)$ \\
Terengganu & $47(2.4 \%)$ \\
Kelantan & $86(4.4 \%)$ \\
Sabah & $151(7.7 \%)$ \\
Sarawak & $160(8.1 \%)$ \\
The Federal Territories (Kuala Lumpur & $208(10.6 \%)$ \\
and Putrajaya) & \\
\hline
\end{tabular}

Notes: *The classifications of ethnicity were referring to the Department of Statistics Malaysia, ${ }^{25}$ where the Bumiputra were Malays combined with other indigenous groups, and Others were Malaysian citizens of other nationalities.

Abbreviation: SD, standard deviation.

Bumiputra, which is the major ethnic group in Malaysia referring to Malays and other indigenous groups $(\mathrm{n}=1364$, $69.2 \%$ ), achieved tertiary education as their highest level of education ( $n=811,41.1 \%$ ), employed for wages $(n=934$, $47.4 \%)$, worked in non-healthcare-related areas $(\mathrm{n}=1824$, 92.5\%), with a monthly income of RM 1000 - RM 3999 $(\mathrm{n}=756,38.4 \%)$, and from urban areas $(\mathrm{n}=1502,76.2 \%)$.

The respondents' prior experiences with antibiotic use are shown in Table 2. About $64.5 \%(\mathrm{n}=1272)$ of respondents reported prior use of antibiotics during their lifetime, with $37.0 \% \quad(n=728)$ reported the last use of antibiotics within the past 6 months. About a third of the respondents $(n=648,32.9 \%)$ could not remember their last use of antibiotics. Among the respondents who reported prior use of antibiotics, a high proportion $(n=1200,94.3 \%)$ received an antibiotic prescription after consultation with their doctors or dentists. The main reasons for using antibiotics were fever $(n=603,35.5 \%)$ and respiratory tract infections $(\mathrm{n}=381,22.4 \%)$. Advice on how to take antibiotics was received by $89.9 \%$ $(n=1143)$ of respondents, with the primary source of advice being healthcare professionals. A total of $56.6 \%$ $(n=1116)$ of respondents had engaged in at least one inappropriate practice related to antibiotic use, with the most common being not completing the antibiotic course $(\mathrm{n}=962,48.8 \%)$. A similar proportion of respondents reported other forms of inappropriate practices, such as obtaining antibiotics without a prescription $(n=246$, $12.5 \%$ ), using leftover antibiotics without advice from healthcare professionals $(\mathrm{n}=250,12.7 \%)$, and sharing leftover antibiotics with others $(\mathrm{n}=249,12.6 \%)$. 
Table 2 Prior Experience in Antibiotic Use

\begin{tabular}{|c|c|}
\hline & n (\%) \\
\hline \multicolumn{2}{|l|}{ Last take antibiotics $(n=1971)$} \\
\hline In the last month & 305 (15.5\%) \\
\hline In the last 6 months & $423(21.5 \%)$ \\
\hline In the last year & $218(11.1 \%)$ \\
\hline More than a year ago & $326(16.5 \%)$ \\
\hline Never & $35(1.8 \%)$ \\
\hline Cannot remember & $648(32.9 \%)$ \\
\hline Not sure what antibiotic is & $16(0.8 \%)$ \\
\hline \multicolumn{2}{|l|}{ Source of antibiotics ${ }^{\dagger}(n=1272)$} \\
\hline Prescribed after consultation with doctor & $1132(89.0 \%)$ \\
\hline Prescribed after consultation with dentist & $68(5.3 \%)$ \\
\hline Retail pharmacy/community pharmacy & $43(3.4 \%)$ \\
\hline Retail shop & $5(0.4 \%)$ \\
\hline Friends/family/neighbors & $15(1.2 \%)$ \\
\hline Leftover antibiotics (own/someone's else) & $9(0.7 \%)$ \\
\hline \multicolumn{2}{|l|}{$\operatorname{Reason}_{(s)}$ to take antibiotics ${ }^{\dagger \ddagger}(n=\mid 272)$} \\
\hline Fever & $603(35.5 \%)$ \\
\hline Pain/inflammation & $246(14.5 \%)$ \\
\hline Respiratory tract infection & $381(22.4 \%)$ \\
\hline Urinary tract infection & $57(3.4 \%)$ \\
\hline Skin problems/wounds/cuts & 127 (7.5\%) \\
\hline Dental problem & $84(4.9 \%)$ \\
\hline Diarrhea/vomiting & $93(5.5 \%)$ \\
\hline Others & $47(2.8 \%)$ \\
\hline Do not know & $10(0.6 \%)$ \\
\hline Cannot remember & $50(2.9 \%)$ \\
\hline \multicolumn{2}{|l|}{$\begin{array}{l}\text { Get advice on how to take antibiotics }{ }^{\dagger} \\
(n=1272)\end{array}$} \\
\hline Yes & II 43 (89.9\%) \\
\hline No & $80(6.3 \%)$ \\
\hline Cannot remember & 49 (3.9\%) \\
\hline \multicolumn{2}{|l|}{ Source(s) of advice ${ }^{\dagger \ddagger}(n=1 \mid 43)$} \\
\hline Doctor & $960(63.2 \%)$ \\
\hline Pharmacist & $256(16.8 \%)$ \\
\hline Nurse & $|2|(8.0 \%)$ \\
\hline Dentist & 79 (5.2\%) \\
\hline Friends/family/neighbors & $46(3.0 \%)$ \\
\hline Patient information leaflet & 29 (1.9\%) \\
\hline Mass media & $18(1.2 \%)$ \\
\hline Social media & II (0.7\%) \\
\hline \multicolumn{2}{|l|}{ Inappropriate practices } \\
\hline \multicolumn{2}{|l|}{ Obtained antibiotics without } \\
\hline \multicolumn{2}{|l|}{ a prescription $(n=1971)$} \\
\hline Yes & $246(12.5 \%)$ \\
\hline No & $1705(86.5 \%)$ \\
\hline Not answered & $20(1.0 \%)$ \\
\hline
\end{tabular}

(Continued)
Table 2 (Continued).

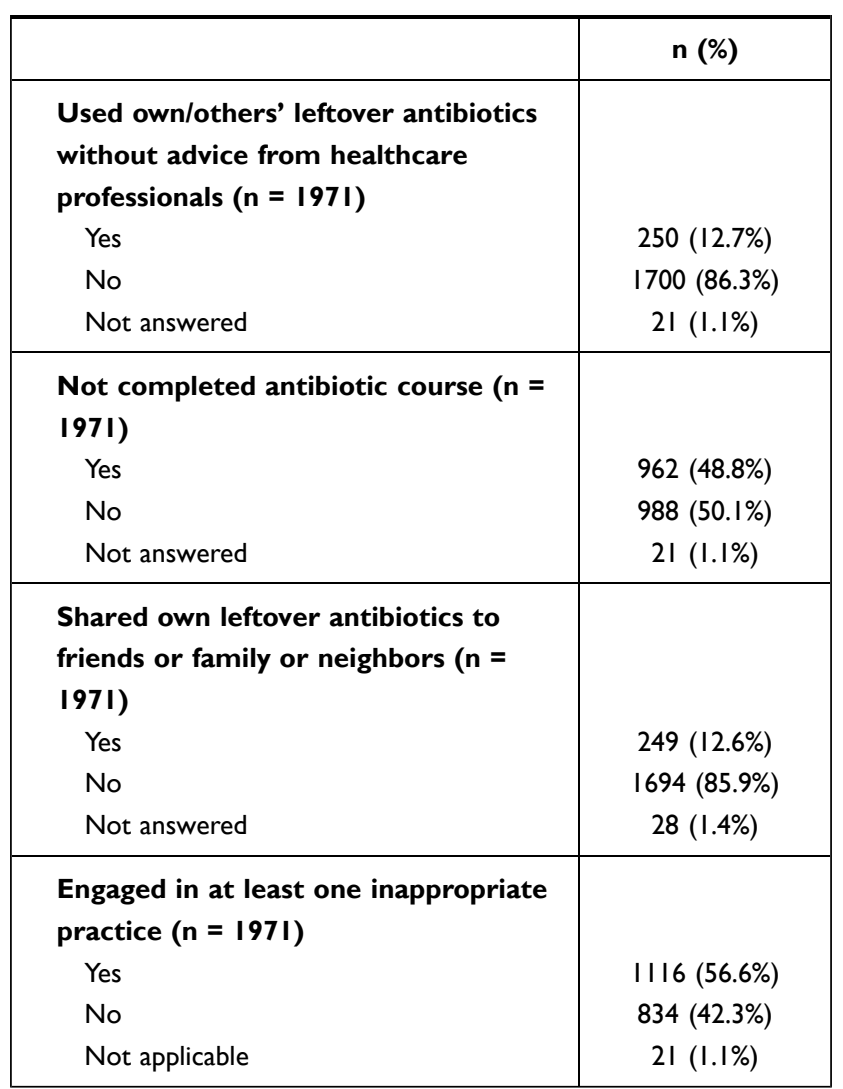

Notes: ${ }^{\dagger}$ Only those who reported taking antibiotics were required to answer these questions. ${ }^{\ddagger}$ Respondents could choose more than one answer.

The mean knowledge score for antibiotic use was $5.65 \pm$ 2.74 out of 12 (range $0-12$ ), and the mean score of knowledge on antibiotic resistance was $2.92 \pm 2.00$ out of 8 (range $0-8$ ). The mean total knowledge score was $8.57 \pm 4.24$ out of 20 (range, 0-20). Respondents who had engaged in at least one inappropriate practice and those who reported not completing their antibiotic course had significantly lower mean total knowledge scores $(8.11 \pm 4.00$ versus $9.26 \pm 4.40, \mathrm{p}<0.001$ and $8.09 \pm 3.93$ versus $9.10 \pm 4.42, \mathrm{p}<0.001$, respectively), compared to those who did not.

Table 3 shows respondents' knowledge of antibiotic use and resistance. In terms of knowledge on antibiotic use, threequarters $(n=1494,75.8 \%)$ of the respondents knew that antibiotics are medicines that can kill bacteria. However, only a small percentage of them knew that antibiotics cannot be used to treat viral infections $(n=407,20.6 \%)$ and do not work on most colds and coughs $(n=439,22.3 \%)$. Slightly more than half of them were correct when asked if "It is okay to stop taking antibiotics when symptoms are improving" (n=1122, 


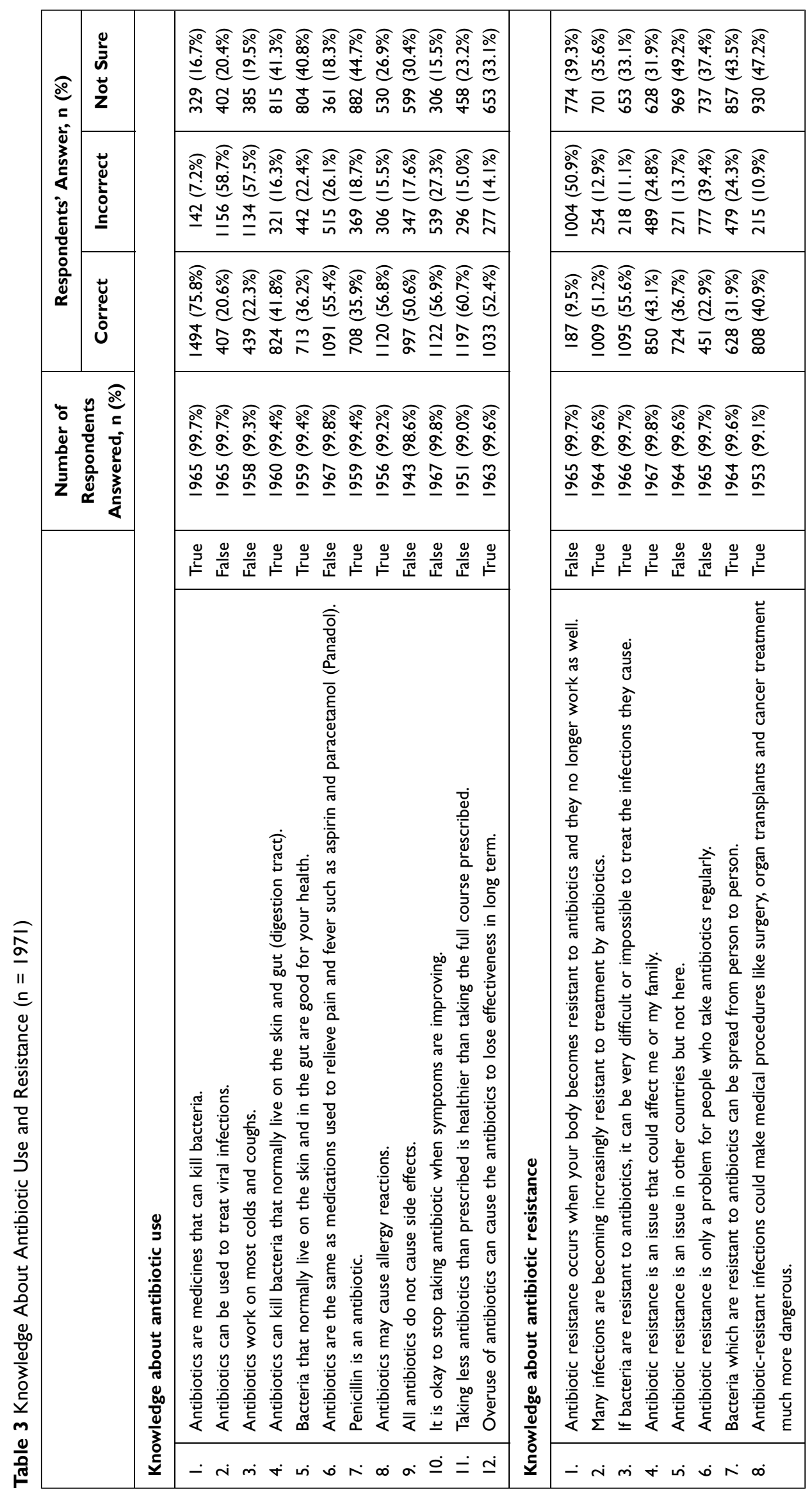


Table 4 Expectation on Antibiotics to Be Prescribed for the Listed Common Symptoms $(n=1971)$

\begin{tabular}{|c|c|c|c|c|c|}
\hline & & \multirow[t]{2}{*}{ Number of Respondents Answered, n (\%) } & \multicolumn{3}{|c|}{ Respondents' Answer, n (\%) } \\
\hline & & & Yes & No & Not Sure \\
\hline I. & Fever & I95I (99.0\%) & $1239(62.9 \%)$ & $588(29.8 \%)$ & $124(6.3 \%)$ \\
\hline 2. & Colds or flu & $1938(98.3 \%)$ & $1003(50.9 \%)$ & 767 (38.9\%) & $168(8.5 \%)$ \\
\hline 3. & Cough & 1932 (98.0\%) & 945 (47.9\%) & 785 (39.8\%) & $202(10.2 \%)$ \\
\hline 4. & Runny nose with clear mucus & $1930(97.9 \%)$ & $576(29.2 \%)$ & $996(50.5 \%)$ & $358(18.2 \%)$ \\
\hline 5. & Runny nose with green mucus & 1932 (98.0\%) & $976(49.5 \%)$ & $555(28.2 \%)$ & $40 \mathrm{I}(20.3 \%)$ \\
\hline 6. & Sore throat & I94I (98.5\%) & II 28 (57.2\%) & 47I (23.9\%) & $342(17.4 \%)$ \\
\hline 7. & Ear infection & I94I (98.5\%) & $1028(52.2 \%)$ & $620(31.5 \%)$ & $293(14.9 \%)$ \\
\hline
\end{tabular}

$56.9 \%)$, "Taking less antibiotics than prescribed is healthier than taking the full course prescribed" ( $n=1197,60.7 \%)$, and "Overuse of antibiotics can cause antibiotics to lose effectiveness in long term" ( $\mathrm{n}=1033,52.4 \%)$. In terms of knowledge on antibiotic resistance, only $9.5 \%(n=187)$ of the respondents answered "Antibiotic resistance occurs when your body becomes resistant to antibiotics and they no longer work as well" correctly. However, it is important to note that more than one-third of respondents selected the "unsure" option for questions related to the seriousness and threat of antibiotic resistance to self or family ( $\mathrm{n}=628,31.9 \%$ ), the whole community including own countries $(\mathrm{n}=969,49.2 \%)$, and if it can make medical procedures much more dangerous ( $n=930,47.2 \%)$, suggesting low awareness regarding antibiotic resistance.

Table 4 shows that the majority of the respondents expected an antibiotic to be prescribed for common selflimiting symptoms such as fever $(n=1239,62.9 \%)$, sore throat $(n=1128,57.2 \%)$, cold or flu $(n=1003,50.9 \%)$, runny nose with green mucus $(\mathrm{n}=976,49.5 \%)$, and cough ( $\mathrm{n}=945,47.9 \%$ ). Respondents who answered knowledge statements for "Antibiotics can be used to treat viral infections" and "Antibiotics work on most colds and coughs" correctly were less likely to expect an antibiotic to be prescribed for their cold, flu, or cough $(\chi 2=25.97$, $\mathrm{p}<0.001$ and $\chi 2=197.80, \mathrm{p}<0.001$, respectively), compared to those who answered these statements incorrectly.

From Table 5, respondents who scored significantly higher in the total knowledge score on antibiotic use and resistance were more likely to disagree with the statements of being less satisfied with the doctor's visit if they expect an antibiotic but do not receive one, would rather take an antibiotic that may not be needed than wait to see if they will get better without it, and would visit another doctor if the doctor does not prescribe an antibiotic when they think one is necessary $(\mathrm{p}<0.001)$. A high percentage of respondents $(n=1474,74.94 \%)$ agreed or strongly agreed that they expect the doctor to discuss with them the need for an antibiotic rather than just giving them a prescription. These respondents had significantly higher total knowledge scores $(9.03 \pm 4.21)$ than those in respondents who were neutral $(6.62 \pm 3.91)(\mathrm{p}<0.001)$; however, the scores were not significantly higher than those in respondents who disagreed with this statement $(8.29 \pm 4.00)$.

\section{Discussion}

This was a nationwide survey conducted in Malaysia to assess the knowledge, expectations, and practices related to antibiotic use among Malaysians. The large sample size recruited from each state based on the basic demographic characteristics enabled a better representation of Malaysia's general public, especially the inclusion of both urban and rural areas, which was not done in previous local studies. This study also assessed the general public's knowledge of antibiotic resistance, which has been infrequently assessed in previous studies. The findings of this study revealed important knowledge gaps regarding antibiotic use and resistance, and inappropriate expectations for antibiotic prescriptions for self-limiting symptoms among the general public in Malaysia.

The majority of the respondents in this study reported that their source of antibiotics was following a prescription after a consultation with physicians; however, $12.5 \%$ of them had at some time obtained antibiotics without a prescription. Some earlier studies, both locally and in other countries, have shown that the prevalence of obtaining antibiotics without a prescription ranges between 4.5 to $38 \% .^{10,11,16-18,39,40}$ This is a worrying trend, as it suggests that antibiotics were possibly purchased illegally either from a reliable or unreliable source. If this situation goes unmonitored, the misuse of antibiotics can lead to a further increase in antibiotic resistance. ${ }^{3}$ As a small number of respondents admitted to obtaining antibiotics from community pharmacies, the need to further enforce the current regulations regarding the accessibility of antibiotics in 
Table 5 Respondents' Mean Total Knowledge Score and Expectation to Discuss with Doctor on Antibiotic Use

\begin{tabular}{|c|c|c|c|c|c|}
\hline & & & n (\%) & $\begin{array}{l}\text { Mean total } \\
\text { Knowledge } \\
\text { Score, } \pm \text { SD }\end{array}$ & p value \\
\hline \multirow[t]{3}{*}{ I. } & \multirow{3}{*}{$\begin{array}{l}\text { If I expect an antibiotic, I am less satisfied with the doctor } \\
\text { visit if I do not receive one. }(n=1962)\end{array}$} & Agree/Strongly Agree & 448 (22.83\%) & $8.47 \pm 3.75$ & \multirow[t]{3}{*}{$\mathrm{p}<0.00 \mathrm{I}^{*}$} \\
\hline & & Neutral & $558(28.44 \%)$ & $7.35 \pm 4.03$ & \\
\hline & & $\begin{array}{l}\text { Disagree/Strongly } \\
\text { Disagree }\end{array}$ & 956 (48.73\%) & $9.35 \pm 4.40$ & \\
\hline \multirow[t]{3}{*}{2.} & \multirow{3}{*}{$\begin{array}{l}\text { I would rather take an antibiotic that may not be needed } \\
\text { than wait to see if I will get better without it. }(n=1967)\end{array}$} & Agree/Strongly Agree & 336 (I7.08\%) & $8.21 \pm 3.99$ & \multirow[t]{3}{*}{$\mathrm{p}<0.00 \mathrm{I}^{*}$} \\
\hline & & Neutral & $396(20.13 \%)$ & $6.94 \pm 3.88$ & \\
\hline & & $\begin{array}{l}\text { Disagree/Strongly } \\
\text { Disagree }\end{array}$ & I 235 (62.78\%) & $9.20 \pm 4.26$ & \\
\hline \multirow[t]{3}{*}{3.} & \multirow{3}{*}{$\begin{array}{l}\text { If a doctor does not prescribe an antibiotic when I think } \\
\text { one is needed, I will visit another doctor. }(n=\mid 967)\end{array}$} & Agree/Strongly Agree & 431 (2I.91\%) & $8.45 \pm 4.17$ & \multirow[t]{3}{*}{$\mathrm{p}<0.00 \mathrm{I}^{*}$} \\
\hline & & Neutral & 365 (I8.52\%) & $7.26 \pm 4.01$ & \\
\hline & & $\begin{array}{l}\text { Disagree/Strongly } \\
\text { Disagree }\end{array}$ & II7I (59.53\%) & $9.03 \pm 4.25$ & \\
\hline \multirow[t]{3}{*}{4.} & \multirow{3}{*}{$\begin{array}{l}\text { I expect the doctor to discuss with me regarding the need } \\
\text { of an antibiotic for my symptoms, rather than just giving me } \\
\text { a prescription. }(n=1967)\end{array}$} & Agree/Strongly Agree & I 474 (74.94\%) & $9.03 \pm 4.21$ & \multirow[t]{3}{*}{$\mathrm{p}<0.00$ I* $^{*}$} \\
\hline & & Neutral & $320(16.27 \%)$ & $6.62 \pm 3.91$ & \\
\hline & & $\begin{array}{c}\text { Disagree/Strongly } \\
\text { Disagree }\end{array}$ & $173(8.80 \%)$ & $8.29 \pm 4.00$ & \\
\hline
\end{tabular}

Notes: Test used = One-way ANOVA test. *Significant with $\mathrm{p}<0.05$.

Abbreviation: SD, standard deviation.

Malaysia was highlighted. Furthermore, other ways of obtaining antibiotics without a prescription corresponded to the findings of engagement in other inappropriate practices of using and sharing own or others' leftover antibiotics without advice from healthcare providers among the respondents in this and previous studies. ${ }^{10,11,16}$ Given that community pharmacists were reported to have a positive attitude in participating in antimicrobial stewardship, they could play a vital role in limiting self-medication with antibiotics among the public by educating them on its risks. ${ }^{12,41}$

One noteworthy finding in this study was that nearly half of the respondents had not completed their antibiotic course in the past. A similar finding was also observed in a few other studies. $^{39,40,42-45}$ A few local studies revealed that $22.3 \%$ to $55.2 \%$ would discontinue antibiotics once their symptoms subsided. ${ }^{11,16-18,39}$ All these factors might explain why they had residual antibiotics. Reasons cited for self-medication and not consulting physicians on the use of leftover antibiotics included assumptions of the illness as a minor health issue, high costs and inconvenience associated with visiting a physician, past experience with a similar illness, beliefs that antibiotics can speed up recovery for all illnesses or prevent infection, and lack of awareness of the dangers and consequences of inappropriate antibiotic use. ${ }^{11,46,47}$ Inappropriate practices related to antibiotic use among the general public in Malaysia could be reduced by improving their knowledge of antibiotic use and resistance, because the findings from this study as well as those from previous studies have shown that respondents who had not completed an antibiotic course or had engaged in inappropriate practices had significantly lower knowledge scores. ${ }^{39,44,48}$

In this study, the knowledge of antibiotic use and antibiotic resistance was lower than that of earlier local studies. ${ }^{17,20}$ Different local studies have reported vast differences in knowledge regarding antibiotic use in the past, ranging from poor to good knowledge. ${ }^{14-16,18}$ Although most respondents knew that antibiotics can kill bacteria, a good number still believed that antibiotics can treat viral infections, including colds and coughs, as seen in previous studies. ${ }^{16,17,25,30,42-45,49}$ The common use of the term "germs" instead of "bacteria" or "virus" by healthcare providers and inconsistency in prescribing antibiotics for similar 
illnesses by physicians may have caused such confusion among patients. ${ }^{16,50}$ Similar to previous studies, a considerable proportion of the general public still incorrectly believed that they could stop taking antibiotics when their symptoms improved and that taking fewer antibiotics than prescribed was healthier than taking the full course. $^{10,11,16-18,25,42}$ Patients perceived that antibiotics are used to shorten the illness duration, or that taking fewer antibiotics allows the body's immune system to fight infections naturally. ${ }^{21}$ This was further reflected by the low knowledge of antibiotic resistance, where a large proportion of the respondents in this study incorrectly believed that antibiotic resistance occurs when the body becomes resistant to antibiotics and that antibiotic resistance is only a problem for people who take antibiotics regularly. These proportions were higher than those reported in other countries. ${ }^{10,25,26,51,52}$ A misconception was found where patients thought that someone's body instead of a bacteria would build immunity after much exposure to certain antibiotics, which led to the body's resistance to fight against the infections, as in the case of drug addiction. ${ }^{53}$ In addition, half of the respondents from this study were unaware of the seriousness of antibiotic resistance that could affect them, their families, and their communities. All these findings not only highlight the existence of an incomplete understanding of antibiotic use and resistance among the general public, but also reflected the discrepancies in the understanding between patients and clinicians, and pointed to the need to address these issues when changing the current strategies to provide more effective education to the general public. ${ }^{53}$

Similar to previous local studies, more than half of the respondents in this study expected antibiotics to be prescribed for certain self-limiting symptoms..$^{10,11,14,16-18}$ Respondents in this study who knew that antibiotics are not for viral infections were less likely to expect antibiotics for cough, cold, or flu, which is in line with the findings in other studies. ${ }^{30,31}$ Insufficient knowledge of self-limiting symptoms and the lack of awareness about self-management among the general public might be the cause of unnecessary visits to physicians and inappropriate expectations of antibiotics. ${ }^{29}$ In addition, inconsistencies in antibiotic prescription practices among physicians and the lack of discussions with patients may cause patients to be confused about the need for antibiotics for certain illnesses. ${ }^{31}$ Three-quarters of the respondents in this study and a study in Hong Kong expected the doctor to discuss with them regarding the need for an antibiotic. ${ }^{26}$ Effective communication between physicians and patients in discussing the illness, explaining the unneeded antibiotics, and contingency plans successfully reduced inappropriate antibiotic prescription. ${ }^{54}$ Overall, it is notable that improving the public's knowledge may influence expectations related to antibiotic use. Therefore, important key messages from the knowledge gaps of respondents, which consist of the role of antibiotics, completion of the antibiotic course, understanding of mechanism and threat of antibiotic resistance, and own responsibility should be considered when promoting prudent use of antibiotics. Various promotional methods should be used to ensure the accessibility of effective educational messages by different groups in the general public.

One of the strengths of this study is that respondents were recruited from all states in Malaysia, including both the urban and rural areas of each state and federal territories, and quota sampling was applied to age group, gender, and ethnicity to ensure a better representation of the Malaysian general public. Second, unlike other studies conducted in healthcare facilities, this survey was conducted in a variety of public areas that were non-healthcare facilities, resulting in high recruitment of heterogeneous respondents from non-healthcare backgrounds, which minimized the bias on the results collected. Third, as Malaysia is a multi-ethnic country, the questionnaire was prepared in four different languages to minimize bias due to language barriers. These key factors contribute to the increase in the generalizability of the findings from this study to the general population. However, as the recruitment of respondents was mainly dependent on their willingness to answer, this may have caused a slight under-representation of certain target populations such as men and older adults. In addition, there might have been a possibility of recall bias among the respondents, particularly when answering questions related to prior antibiotic use and experience.

\section{Conclusion}

The high rate of non-completion of antibiotic courses and lack of knowledge on antibiotic use and resistance observed in this study highlighted important knowledge gaps among the general public in Malaysia. There was confusion regarding the role of antibiotics, the full mechanism of antibiotic resistance, and the low perceived threat of antibiotic resistance among the public. Better knowledge may influence the public's expectations of discussing antibiotic use with physicians and being prescribed an antibiotic, and engagement in inappropriate practices. Hence, the important key information identified in this study should be incorporated into future educational strategies and public health campaigns to effectively correct misperceptions and achieve public health awareness. 


\section{Abbreviations}

WHO, World Health Organization; UKM, Universiti Kebangsaan Malaysia; SPSS, Statistical Package for Social Sciences; ANOVA, Analysis of Variance; SD, Standard deviation.

\section{Data Sharing Statement}

The datasets used and/or analysed during the current study are available from the corresponding author on reasonable request.

\section{Ethics Approval and Consent to Participate}

Ethical approval for this study was obtained from the Universiti Kebangsaan Malaysia Research Ethics Committee (reference number: UKM PPI/111/8/JEP2018-717). Written consent was obtained from the respondents prior to answering the questionnaire.

\section{Acknowledgments}

We would like to thank all respondents for their time in this study. We would also like to express our sincere appreciation to the research assistant (Hanisah Lafti) and all the enumerators for their assistance in this study.

\section{Author Contributions}

All authors made substantial contributions to conception and design, acquisition of data, or analysis and interpretation of data; took part in drafting the article or revising it critically for important intellectual content; agreed to submit to the current journal; gave final approval of the version to be published; and agree to be accountable for all aspects of the work.

\section{Funding}

This study was supported by a university grant from Universiti Kebangsaan Malaysia (DCP-2017-003/5).

\section{Disclosure}

The authors declare that they have no conflicts of interest in this work.

\section{References}

1. World Health Organization. Global Action Plan on Antimicrobial Resistance. WHO Press; 2015:1-28.

2. CDC. Antibiotic resistance threats in the United States, 2013. Current. 2013;2013:114.

3. Dadgostar P. Antimicrobial resistance: implications and costs. Infect Drug Resist. 2019;12:3903-3910. doi:10.2147/IDR.S234610

4. Gajdács M. The concept of an ideal antibiotic: implications for drug design. Molecules. 2019;24(5):892. doi:10.3390/molecules24050892
5. Ventola CL. The antibiotic resistance crisis: part 1: causes and threats. Pharm Ther. 2015;40(4):277-283.

6. Gualano MR, Gili R, Scaioli G, Bert F, Siliquini R. General population's knowledge and attitudes about antibiotics: a systematic review and meta-analysis. Pharmacoepidemiol Drug Saf. 2015;24(1):2-10. doi: $10.1002 /$ pds. 3716

7. Kurniawan K, Posangi J, Rampengan N. Association between public knowledge regarding antibiotics and self-medication with antibiotics in Teling Atas Community Health Center, East Indonesia. Med J Indones. 2017;26:62-69. doi:10.13181/mji.v26i1.1589

8.. Sirijoti K, Hongsranagon P, Havanond P, Pannoi W. Assessment of knowledge attitudes and practices regarding antibiotic use in Trang Province, Thailand. J Heal Res. 2014;28(5):299-307.

9. Aslam A, Gajdács M, Zin CS, et al. Evidence of the practice of self-medication with antibiotics among the lay public in low-and middle-income countries: a scoping review. Antibiotics. 2020;9 (9):597. doi:10.3390/antibiotics9090597

10. Choo SJ, Chang CT, Lee JCY, et al. A cross-sectional study on public belief, knowledge and practice towards antibiotic use in the state of perak, Malaysia. J Infect Dev Ctries. 2018;12(11):960-969. doi:10.3855/ jidc. 10723

11. Hassali MA, Arief M, Saleem F, et al. Assessment of attitudes and practices of young Malaysian adults about antibiotics use: a cross-sectional study. Pharm Pract (Granada). 2017;15(2):1-7. doi:10.18549/PharmPract.2017.02.929

12. Khan MU, Hassali MAA, Ahmad A, Elkalmi RM, Zaidi STR, Dhingra S. Perceptions and practices of community pharmacists towards antimicrobial stewardship in the state of Selangor, Malaysia. PLoS One. 2016;11(2):1-10. doi:10.1371/journal.pone.0149623

13. Press Statement DG of Health 4th September 2016 - medication must not be sold without prescription. Available from: https://kpkesihatan.com/ 2016/09/04/press-statement-dg-of-health-4th-september-2016medication-must-not-be-sold-without-prescription/. Accessed August 21, 2021.

14. Ab Halim NAA, Chang CT, Chan HK, Hassali MA, Nouri A. Knowledge and attitudes concerning antibiotic use and resistance among the public in Pulau Pinang, Malaysia. Malaysian J Med Sci. 2018;25(6):141-147. doi:10.21315/mjms2018.25.6.15

15. Islahudin F, Madihah A, Tamezi A, Shah NM. Knowledge, attitudes and practices about antibiotic use among the general public in Malaysia. Southeast Asian J Trop Med Public Heal. 2014;45(6):1474-1482.

16. Oh AL, Hassali M, Al-Haddad M, Syed Azhar S, Shafie A, Awaisu A. Public knowledge and attitudes towards antibiotic usage: a cross-sectional study among the general public in the state of Penang, Malaysia. $J$ Infect Dev Ctries. 2011;5:338-347. doi:10.3855/jidc.1502

17. Lim KK, Teh CC. A cross sectional study of public knowledge and attitude towards antibiotics in Putrajaya, Malaysia. South Med Rev. 2012;5(2):26-33.

18. Qamar M, Abdullah NS, Khan J, Mahmud A, Ahmad A. Knowledge and attitude towards antibiotic usage among general public in Shah Alam, Malaysia. UKJ Pharm Biosci. 2014;2(6):60-66. doi:10.20510/ukjpb/2/i6/ 91175

19. Irawati L, Alrasheedy AA, Hassali MA, Saleem F. Low-income community knowledge, attitudes and perceptions regarding antibiotics and antibiotic resistance in Jelutong District, Penang, Malaysia: a qualitative study. BMC Public Health. 2019;19(1):1-15. doi:10.1186/s12889-019-7718-9

20. Kong LS, Islahudin F, Muthupalaniappen L, Chong WW. Knowledge and expectations on antibiotic use among older adults in Malaysia: a cross-sectional survey. Geriatrics. 2019;4(4):61. doi:10.3390/ geriatrics4040061

21. Bakhit M, Del Mar C, Gibson E, Hoffmann T. Exploring patients' understanding of antibiotic resistance and how this may influence attitudes towards antibiotic use for acute respiratory infections: a qualitative study in Australian general practice. BMJ Open. 2019;9(3):e026735. doi:10.1136/bmjopen-2018-026735 
22. McCullough A, Parekh S, Rathbone J, Del Mar C, Hoffmann T. A systematic review of the public's knowledge and beliefs about antibiotic resistance. J Antimicrob Chemother. 2016;71(1):27-33. doi:10.1093/jac/dkv310

23. Aslam A, Gajdács M, Zin CS, Rahman NSBA, Ahmed SI, Jamshed SQ. Public awareness and practices towards self-medication with antibiotics among the Malaysian population. A development of questionnaire and pilot-testing. Antibiotics. 2020;9(2):97. doi:10.3390/antibiotics9020097

24. Gajdács M, Paulik E, Szabó A. Public knowledge, attitude and practices towards antibiotics and antibiotic resistance: a cross-sectional study in Szeged District, Hungary. Acta Pharm Hung. 2020;90(1):5-14. doi:10.33892/aph.2020.90.5-14

25. World Health Organization. Antibiotic Resistance: Multi-Country Public Awareness Survey. WHO Press; 2015:1-51. Available from: http://apps.who.int/iris/bitstream/10665/194460/1/9789241509817 eng.pdf?ua=1. Accessed October 13, 2021.

26. Bacon-Shone J. General Public's Knowledge, Attitude and Practice Survey on Antimicrobial Resistance 2016/17; Centre for Health Protection. Department of Health. The Government of Hong Kong Special Administrative Region. Released in 30 November 2017. Available from: https://www.chp.gov.hk/files/pdf/kap_on_amr main_report.pdf. Assessed October 13, 2021.

27. Carter RR, Sun J, Jump RLP. A survey and analysis of the American public's perceptions and knowledge about antibiotic resistance. Open Forum Infect Dis. 2016;3(3):ofw112. doi:10.1093/ofid/ofw112

28. Fletcher-lartey S, Yee M, Gaarslev C, Khan R. Why do general practitioners prescribe antibiotics for upper respiratory tract infections to meet patient expectations: a mixed methods study. BMJ Open. 2016;6:1-8. doi:10.1136/bmjopen-2016-012244

29. Freidoony L, Kim CB, Haghani H, et al. From visiting a physician to expecting antibiotics: korean perspectives and practices toward respiratory tract infections. J Korean Med Sci. 2017;32(2):278-286. doi:10.3346/jkms.2017.32.2.278

30. Gaarslev C, Yee M, Chan G, Fletcher-Lartey S, Khan R. A mixed methods study to understand patient expectations for antibiotics for an upper respiratory tract infection. Antimicrob Resist Infect Control. 2016;5(1):1-9. doi:10.1186/s13756-016-0134-3

31. Davis M, Liu T-L, Taylor Y, et al. Exploring patient awareness and perceptions of the appropriate use of antibiotics: a mixed-methods study. Antibiotics. 2017;6(4):23. doi:10.3390/antibiotics6040023

32. Ministry of Health Malaysia. Malaysian Action Plan on Antimicrobial Resistance (MyAP-AMR) 2017-2021. Ministry of Health Malaysia; 2017:1-51. Available from: https:/www.moh.gov. $\mathrm{my} / \mathrm{moh} /$ resources/Penerbitan/Garis\%20Panduan/Garis\%20panduan \%20Umum\%20(Awam)/National_Action_Plan_-_FINAL_29_june. pdf. Assessed October 13, 2021.

33. Department of Statistics Malaysia. Population and Housing Census of Malaysia. Population Distribution and Basic Demographic Characteristics 2010; 2011.

34. United Nations. Department of Economic and Social Affaris, Population Division. World population prospects 2019, Online Edition. Rev. 1. 2019.

35. Raosoft. Sample Size Calculator. Raosoft Inc; 2004. Available from: http://www.raosoft.com/samplesize.html. Accessed October 13, 2021.

36. Kuzujanakis M, Kleinman K, Rifas-Shiman S, Finkelstein JA. Correlates of parental antibiotic knowledge, demand, and reported use. Ambul Pediatr. 2003;3(4):203-210. doi:10.1367/1539-4409(2003)003<0203:COPAKD>2.0.CO;2

37. Mat Lazim MS. Evolution of Migration for Urban and Rural. Department of Statistics Malaysia; 2020:1-5.
38. IBM Corp. Released 2019. IBM SPSS Statistics for Windows, Version 26.0. Armonk, NY: IBM Corp. 2019.

39. Fatokun O. Exploring antibiotic use and practices in a Malaysian community. Int J Clin Pharm. 2014;36(3):564-569. doi:10.1007/ s11096-014-9937-6

40. Yusef D, Babaa AI, Bashaireh AZ, et al. Knowledge, practices \& attitude toward antibiotics use and bacterial resistance in Jordan: a cross-sectional study. Infect Dis Heal. 2018;23(1):33-40. doi:10.1016/j.idh.2017.11.001

41. Gajdács M, Paulik E, Szabó A. Knowledge, attitude and practice of community pharmacists regarding antibiotic use and infectious diseases: a cross-sectional survey in Hungary (KAPPhA-HU). Antibiotics. 2020;9:2. doi:10.3390/antibiotics9020041

42. Mouhieddine TH, Olleik Z, Itani MM, et al. Assessing the Lebanese population for their knowledge, attitudes and practices of antibiotic usage. J Infect Public Health. 2015;8(1):20-31. doi:10.1016/j. jiph.2014.07.010

43. Abujheisha KY, Al-Shdefat R, Ahmed N, Fouda MI. Public knowledge and behaviours regarding antibiotics use: a survey among the general public. Int J Med Res Heal Sci. 2017;6(6):82-88.

44. Awad AI, Aboud EA. Knowledge, attitude and practice towards antibiotic use among the public in Kuwait. PLoS One. 2015;10 (2):1-15. doi:10.1371/journal.pone.0117910

45. Jifar A, Ayele Y. Assessment of knowledge, attitude, and practice toward antibiotic use among Harar City and its surrounding community, Eastern Ethiopia. Interdiscip Perspect Infect Dis. 2018;2018:1-7. doi:10.1155/2018/8492740

46. Alhomoud F, Aljamea Z, Almahasnah R, Alkhalifah K, Basalelah L, Alhomoud FK. Self-medication and self-prescription with antibiotics in the Middle East - do they really happen? A systematic review of the prevalence, possible reasons, and outcomes. Int J Infect Dis. 2017;57:3-12. doi:10.1016/j.ijid.2017.01.014

47. Nepal G, Bhatta S. Self-medication with antibiotics in WHO Southeast Asian Region: a systematic review. Cureus. 2018;10(4). doi:10.7759/cureus. 2428

48. McNulty CAM, Boyle P, Nichols T, Clappison P, Davey P. Don't wear me out - The public's knowledge of and attitudes to antibiotic use. J Antimicrob Chemother. 2007;59(4):727-738. doi:10.1093/jac/dkl558

49. Kamata K, Tokuda Y, Gu Y, Ohmagari N, Yanagihara K. Public knowledge and perception about antimicrobials and antimicrobial resistance in Japan: a national questionnaire survey in 2017. PLoS One. 2018;13(11):e0207027. doi:10.1371/journal.pone.0207017

50. André M, Vernby $\AA$, Berg J, Lundborg CS. A survey of public knowledge and awareness related to antibiotic use and resistance in Sweden. J Antimicrob Chemother. 2010;65(6):1292-1296. doi:10.1093/jac/dkq104

51. Salm F, Ernsting C, Kuhlmey A, Kanzler M, Gastmeier P, Gellert P. Antibiotic use, knowledge and health literacy among the general population in Berlin, Germany and its surrounding rural areas. PLoS One. 2018;13(2):1-11. doi:10.1371/journal.pone.0193336

52. Prigitano A, Romanò L, Auxilia F, Castaldi S, Tortorano AM. Antibiotic resistance: Italian awareness survey 2016. J Infect Public Health. 2018;11(1):30-34. doi:10.1016/j.jiph.2017.02.010

53. Brookes-Howell L, Elwyn G, Hood K, et al. "The body gets used to them": patients' interpretations of antibiotic resistance and the implications for containment strategies. J Gen Intern Med. 2012;27 (7):766-772. doi:10.1007/s11606-011-1916-1

54. Fleming-Dutra KE, Mangione-Smith R, Hicks LA. How to prescribe fewer unnecessary antibiotics: talking points that work with patients and their families. Am Fam Physician. 2016;94(3):200-202. 


\section{Publish your work in this journal}

Patient Preference and Adherence is an international, peer-reviewed, open access journal that focusing on the growing importance of patient preference and adherence throughout the therapeutic continuum. Patient satisfaction, acceptability, quality of life, compliance, persistence and their role in developing new therapeutic modalities and compounds to optimize clinical outcomes for existing disease states are major areas of interest for the journal. This journal has been accepted for indexing on PubMed Central. The manuscript management system is completely online and includes a very quick and fair peer-review system, which is all easy to use. Visit http:// www.dovepress.com/testimonials.php to read real quotes from published authors. 